\title{
A Mediterranean Diet with an Enhanced Consumption of Extra Virgin Olive Oil and Pistachios Improves Pregnancy Outcomes in Women Without Gestational Diabetes Mellitus: A Sub-Analysis of the St. Carlos Gestational Diabetes Mellitus Prevention Study
}

\author{
Carla Assaf-Balut ${ }^{a, b} \quad$ Nuria García de la Torre ${ }^{a, c} \quad$ Alejandra Duran $^{a, b}$ Manuel Fuentes ${ }^{d}$ \\ Elena Bordiúa, b Laura del Valle ${ }^{a}$ Cristina Familiar $^{a} \quad$ Johanna Valerio ${ }^{a}$ \\ Inés Jiménez $^{a} \quad$ Miguel A. Herraiz $^{\text {b, e }}$ Nuria Izquierdo ${ }^{b, e}$ María J. Torrejon $^{f}$ \\ Maria Ángeles Cuadradob,f Isabel Ortega ${ }^{f} \quad$ Francisco J. Illana $^{f} \quad$ Isabelle Runkle ${ }^{a, b}$ \\ Paz de Miguel ${ }^{a, b}$ Inmaculada Moraga ${ }^{a} \quad$ Carmen Montañez $^{a} \quad$ Ana Barabash $^{a, c}$ \\ Martín Cuesta ${ }^{a, c}$ Miguel A. Rubio ${ }^{a, b}$ Alfonso L. Calle-Pascual ${ }^{a-c}$ \\ a Department of Endocrinology and Nutrition, Hospital Clínico Universitario San Carlos and Instituto de Investigación \\ Sanitaria del Hospital Clínico San Carlos (IdISSC), Madrid, Spain; b Facultad de Medicina, Universidad Complutense de Madrid, \\ Madrid, Spain; 'CCentro de Investigación Biomédica en Red de Diabetes y Enfermedades Metabólicas Asociadas (CIBERDEM), \\ Madrid, Spain; ' Department of Preventive Medicine, Hospital Clínico Universitario San Carlos and Instituto de Investigación \\ Sanitaria del Hospital Clínico San Carlos (IdISSC), Madrid, Spain; ${ }^{e}$ Department of Gynecology and Obstetrics, Hospital Clínico \\ Universitario San Carlos and Instituto de Investigación Sanitaria del Hospital Clínico San Carlos (IdISSC), Madrid, Spain; \\ fDepartment of Clinical Laboratory, Hospital Clínico Universitario San Carlos and Instituto de Investigación Sanitaria del \\ Hospital Clínico San Carlos (IdISSC), Madrid, Spain
}

\section{Keywords}

Mediterranean diet · Extra-virgin olive oil · Pregnancy outcomes

\footnotetext{
Abstract

Aims: The aim of the study was to evaluate the effect of a Mediterranean diet (MedDiet), enhanced with extra virgin olive oil (EVOO) and nuts, on a composite of adverse maternofoetal outcomes of women with normoglycemia during pregnancy. Methods: This was a sub-analysis of the St Carlos gestational diabetes mellitus Prevention Study. Only normoglycemic women were analysed (697). They were random-
}

\begin{tabular}{ll}
\hline KARGER & ( ) 2018 The Author(s) \\
Published by S. Karger AG, Basel & Karger \\
E-Mail karger@karger.com & This article is licensed under the Creative Commons Attribution- \\
www.karger.com/anm & $\begin{array}{l}\text { NonCommercial-NoDerivatives 4.0 International License (CC BY- } \\
\text { NC-ND) (http://www.karger.com/Services/OpenAccessLicense). } \\
\text { Usage and distribution for commercial purposes as well as any dis- } \\
\text { tribution of modified material requires written permission. }\end{array}$
\end{tabular}

ized (at 8-12th gestational weeks) to: standard-care control group (337), where fat consumption was limited to $30 \%$ of total caloric intake; or intervention group (360), where a MedDiet, enhanced with EVOO and pistachios (40-42\% fats of total caloric intake) was recommended. The primary outcome was a composite of maternofoetal outcomes (CMFOs): at least having 1 event of emergency $\mathrm{C}$-section, perineal trauma, pregnancy-induced hypertension and preeclampsia, prematurity, large-for-gestational-age and small-for gestational-age. Results: Crude relative risk showed that the in-

\section{C.A.-B. and N.G.T. contributed equally to this work.}


tervention was associated with a significant reduction in the risk of CMFOs (0.48 [0.37-0.63]; $p=0.0001)$, with a numberneeded-to-treat $=5$. Risk of urinary tract infections, emergency C-sections, perineal trauma, large-for-gestational-age and small-for gestational age new-borns were also significantly reduced. Conclusion: A MedDiet, enhanced with EVOO and nuts, was associated with a risk reduction of CMFOs in over $50 \%$ in normoglycemic pregnant women. Therefore, it might be a potentially adequate diet for pregnant women. Trial registration: Identifier ISRCTN84389045. The study was registered on September 27, 2013. Last edited on September 26, 2018

(c) 2018 The Author(s)

Published by S. Karger AG, Basel

\section{Background}

Maternal nutrition in the peri conceptional and gestational period is a key aspect related to the health of the mother and offspring in both the short and long terms [1-4]. Maternal nutrition can potentially impact placental and foetal growth [5-7]. It can also have permanent negative consequences for the offspring. It is likely that the offspring has a higher risk of type 2 diabetes and cardiovascular diseases in the future [8$11]$.

A body of research describes the need of dietary and supplement intake of folic acid, iron, zinc, calcium, vitamin D and B12 and omega-3 polyunsaturated fatty acids as well as their effect on pregnancy outcomes [3]. Most dietary interventions focus their research on individual nutrients, not dietary patterns, failing to consider nutrient-nutrient interactions. Nevertheless, nutrients are hardly ever consumed in isolation since foods are a mixture of different nutrients. Evidence about the effect of maternal diet on pregnancy outcomes is mostly generated from observational studies. Thus, randomized controlled trials are necessary to increase the evidence base for dietary recommendations during pregnancy.

Nutritional recommendations provided in clinical practice limit the intake of fats to avoid excessive gestational weight gain; however, data on effective dietary interventions are inconclusive [12]. Limitation of fats includes trans and saturated fats and, in our setting, also includes mono- and poly-unsaturated fats. These are present in extra virgin olive oil (EVOO) and nuts, indispensable pillars of the mediterranean diet (MedDiet) [13]. This diet is not associated with weight gain; in fact it is just the opposite [14].
Recently, our research group has shown associations between a MedDiet with an enhanced consumption of EVOO and nuts and a reduction in gestational diabetes mellitus (GDM) incidence [15]. The potentially favourable effects of following this diet during pregnancy in normoglycemic women remain unknown.

The St. Carlos GDM Prevention Study presents a perfect opportunity to study the impact of maternal diet on maternofoetal health in normoglycemic women. This study was set out to compare maternal and neonatal outcomes as well as clinical and biochemical parameters of women who followed nutritional guidelines based on a MedDiet supplemented with EVOO and pistachios versus women who followed guidelines provided in regular clinical practice that limit total fat consumption.

\section{Methods}

Study Design and Study Population

This was a sub-analysis of the St. Carlos GDM Prevention study. It was a single-centre, clinic-based, prospective, randomized, interventional study, with 2 parallel groups that targeted all pregnant women followed by the obstetrics department of the Hospital Clínico San Carlos, Madrid, Spain. It was conducted from January 1st to December 31, 2015. The first woman was included in the study on January 2nd and the last one was included on December 27th. The follow-up until delivery finished on July 20, 2016.

In the current study, inclusion criteria were pregnant women $\geq 18$ years old, fasting glucose levels $<92 \mathrm{mg} / \mathrm{dL}$ in the first gestational visit (8-12th gestational weeks), single gestation, agreement to sign the consent form and normal response to the $75 \mathrm{~g}$ oral glucose tolerance test at 24-28th gestational weeks. Exclusion criteria were women with fasting glucose $\geq 92 \mathrm{mg} / \mathrm{dL}$ in the first gestational visit, gestational age at entry $>14$ th gestational weeks, multiple pregnancy, nut allergy, GDM diagnosis, lost to follow-up until delivery and/or any medical condition that could hamper complying with trial follow-up.

A summarized description of the study design is provided in Figure 1. A total of 2,418 women attending their first gestational visit (8-12th gestational weeks) were assessed for inclusion. They were invited to participate between the 12 and the 14th gestational week. After excluding all ineligible participants, 1,501 women were invited and 1,000 accepted and signed the consent form. At inclusion, women were randomly allocated to the standard care control group $(n=500)$ or the intervention group $(n=500)$. From these, 874 were followed until postpartum discharge: 440 in the standard care control group and 434 in the intervention group. A total of 103 and 74 women, respectively, were excluded for developing GDM. Therefore, 337 (76.6\%) women in the control group and $360(82.9 \%)$ women in the intervention group were included in the final analysis.

The study was approved by the Ethics Committee of Hospital Clínico San Carlos and conducted according to the Helsinki Declaration. All women signed a letter of informed consent. The study was registered at ISRCTN84389045. 


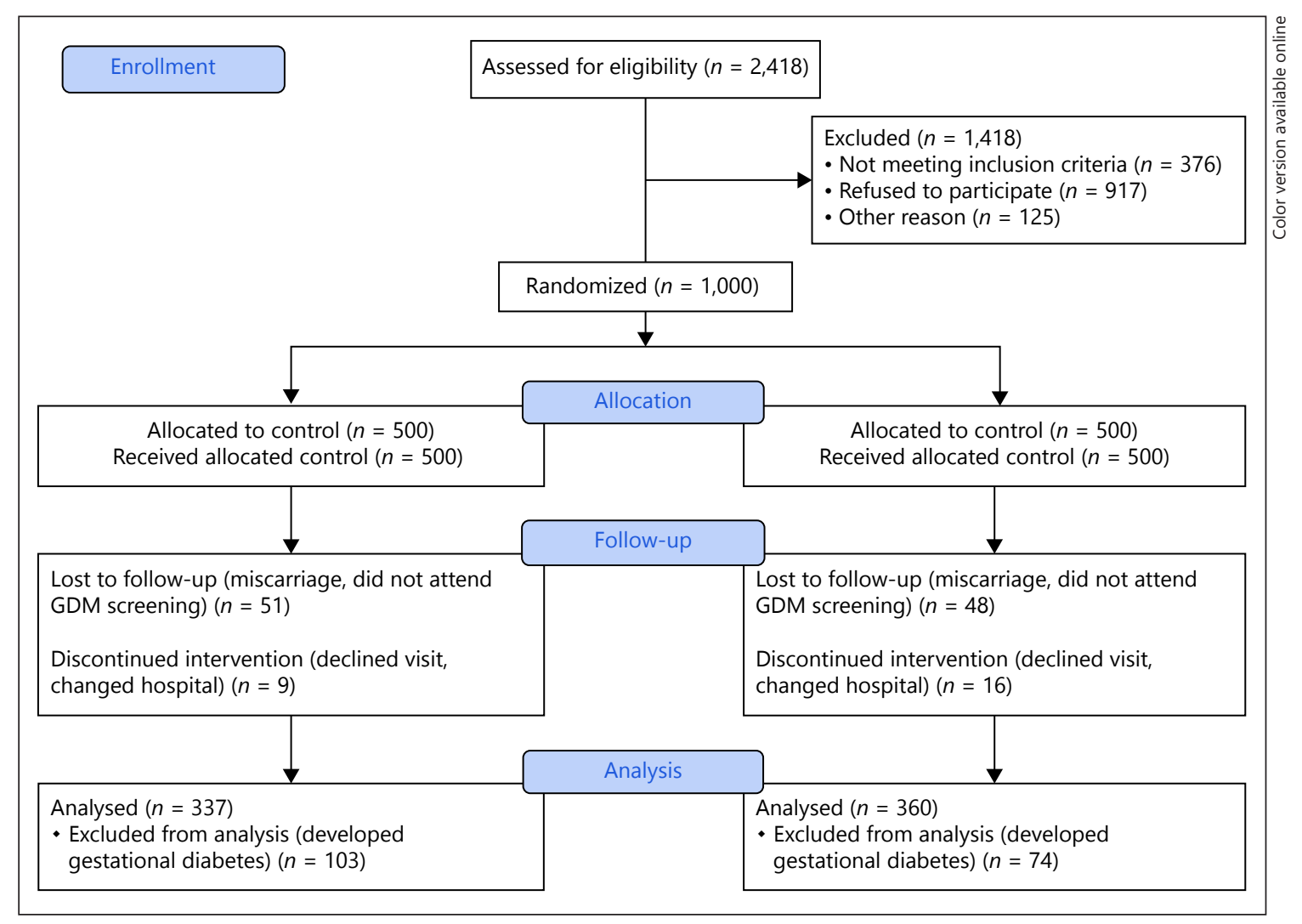

Fig. 1. CONSORT 2010 flow diagram. GDM, gestational diabetes mellitus.

\section{Randomization}

The randomization and sequence allocation were performed by building a stratified randomization with permutated block-randomization, stratified by age, pregestational body mass index (BMI), parity and ethnicity in an allocation ratio of (1:1) in blocks of 4-6.

The allocation remained unknown to the statistician and research assistant. The participants, staff and dietician were aware of the allocation assignments.

\section{Study Outcomes}

Primary Outcome

To compare the incidence of a composite of maternofoetal outcomes (CMFOs) in normoglycemic women who followed 2 different nutritional recommendations - guidelines based on a MedDiet with an enhanced consumption of EVOO oil and nuts versus guidelines provided in regular clinical practice that limit fat consumption. The CMFOs included the following: emergency caesarean section (C-section), perineal trauma, pregnancy-induced hypertension and preeclampsia, prematurity, large-for-gestationalage, and small-for-gestational-age. of:

Secondary outcomes included the comparison between groups

- The incidence of each individual component of the primary outcome.

- Biochemical parameters: glycated haemoglobin $\left(\mathrm{HbA}_{1 \mathrm{c}}\right)$, insulin, fasting glucose, homeostasis assessment model for insulin resistance.
- Clinical parameters (blood pressure and body weight).

- Maternal dietary and physical activity habits throughout pregnancy.

\section{Pregnancy Lifestyle Guidelines}

The intervention and standard care control group received the same basic MedDiet recommendations, as reported in detail previously [15]. They were instructed to be physically active and walk $\geq 30 \mathrm{~min} /$ day. These recommendations were emphasized at each visit for both groups.

\section{Intervention}

Within 1 week of inclusion, participants received lifestyle guidance from dieticians in a 1 -h group session. The key recommendation was to consume a daily intake of $\geq 40 \mathrm{~mL}$ of EVOO and a handful $(25-30 \mathrm{~g})$ of pistachios. They were given $10 \mathrm{~L}$ of EVOO and $2 \mathrm{kgs}$ of roasted pistachios at $12-14$ and 24-28th gestational weeks to ensure adherence.

\section{Standard Care Control Group}

This group received nutritional guidelines currently provided in local antenatal clinics of our setting as part of pregnancy standard care [16]. Midwives highlighted the importance of limiting the consumption of dietary fat, including EVOO and nuts.

\section{Data Collection}

- Maternal Lifestyle and Dietary Assessment 
a) Two semi-quantitative questionnaires were applied to evaluate lifestyle, dietary habits and compliance to the intervention: the diabetes nutrition and complications trial [17] and MedDiet adherence screener (MEDAS) questionnaire [18]. The diabetes nutrition and complications trial was used to evaluate physical activity and general healthy eating habits, assessed by the Nutrition Score. The MEDAS questionnaire was applied to evaluate the adherence to a MedDiet. However, 2 items in this questionnaire (moderate alcohol intake and juice consumption) are discouraged during pregnancy. A detailed description of how lifestyle and diet were evaluated has been published previously [15].

b) Urinary hydroxytyrosol levels and plasma gamma-tocopherol were measured to evaluate compliance to EVOO and pistachio consumption respectively. Their levels have been previously reported to adequately correlate with the consumption of each of EVOO [19] and pistachio [20]. These were measured at baseline and at $24-28$ gestational weeks in $10 \%$ of participants randomly selected from both groups.

- Maternal Body Weight and Gestational Weight Gain

Weight gain was based on self-referred pregestational body weight. It was evaluated at $12-14$ th, $24-28$ th and $36-38$ th gestational weeks (or last weight recorded before delivery). Adequate gestational weight gain was defined according to pregestational BMI as follows: normal weight $\left(<25 \mathrm{~kg} / \mathrm{m}^{2}\right), 9 \mathrm{~kg}$; overweight women $\left(25-29.9 \mathrm{~kg} / \mathrm{m}^{2}\right), 6 \mathrm{~kg}$; class I obesity (30-34.9), $3 \mathrm{~kg}$; and class II obesity $\geq 35 \mathrm{~kg} / \mathrm{m}^{2}, 0 \mathrm{~kg}$ [21]. Weight gain $3 \mathrm{~kg}$ below the designated target according to BMI was categorized as insufficient weight gain. Weight gain $3 \mathrm{~kg}$ above the designated target according to BMI was categorized as excessive weight gain [21-23]. At each visit, the dietary recommendations were individualized to fit gestational weight gain recommendations according to pregestational BMI, in the context of usual recommendations. When gestational weight gain exceeded the goal, nutritional recommendations were given to reduce the caloric content of their diet.

- Maternal Complications. Pregnancy-induced hypertension, preeclampsia, albuminuria and urinary tract infections (number of events requiring antibiotic treatment).

- Obstetric Complications. Type of delivery (vaginal, instrumental or caesarean section) and perineal trauma.

- Anthropometric measures and health status of new-borns. Birth weight and height, large-for-gestational-age, small-for-gestational-age, $\mathrm{pH}$ cord blood, Apgar score, neonatal hypoglycaemia, hyperbilirubinemia, respiratory distress and neonatal ICU admission.

To obtain information about new-borns and complications during delivery, obstetric records were reviewed after delivery.

\section{Follow-Up}

All women were followed up taking advantage of their scheduled standard-practice laboratory appointments. The number of visits was similar in both groups: at $12-14$ th, 24-28th, 36-38th gestational weeks and delivery.

\section{Biochemistry}

Blood was drawn between 08.00 and 09.00 a.m., after an overnight fast. The following data was determined: $\mathrm{HbA}_{1 \mathrm{c}}$, standardized by the International Federation of Clinical Chemistry and Laboratory Medicine; serum insulin; homeostasis assessment model for insulin resistance, calculated as glucose $(\mathrm{mmol} / \mathrm{L}) \times$ insulin $(\mu \mathrm{UI} / \mathrm{mL}) / 22.7$; and fasting glucose.
Urine Hydroxytyrosol levels and serum gamma-tocopherol were measured as described previously [15].

\section{Sample Size}

For sample size calculation, the primary end-point was the incidence of CMFOs. We estimated that 315 women would be required per group to provide statistical power of $80 \%$ (2-tailed, aerror of 0.05$)$, detecting a relative risk (RR) reduction of at least $30 \%$.

\section{Statistical Analysis}

Discrete variables are presented with their frequency and percentage distribution, continuous variables by their mean and SD $( \pm$ SD) when normally distributed, and with median and interquartile range when not. All primary analyses were performed on an intention-to-treat basis. Comparison between groups for categorical variables was evaluated using the $\chi^{2}$ test. For continuous variables, measures were compared with Student $t$ test or the Mann-Whitney $U$ test if distribution of quantitative variables was not normal, as verified by the Shapiro-Wilk test. The difference of mean values between groups for each analysed variable is given as $95 \% \mathrm{CI}$.

The magnitude of association between study groups and binary outcomes was evaluated using the RR and 95\% CI.

Logistic regression analyses were used to assess the effect of the intervention on adverse maternal and neonatal outcomes. The method proposed by Zhou for estimating RR and its CI was conducted.

The number-needed-to-treat (NNT) was calculated as 1/absolute risk reduction.

All $p$ values are 2 -tailed at less than 0.05 . Analyses were performed using SPSS, version 21 (SPSS, Chicago, IL, USA).

\section{Results}

Demographic, clinical and anthropometric characteristics at baseline are shown in Table 1. No significant differences were observed between both groups of women.

Table 2 shows the evolution of lifestyle patterns throughout the pregnancy as revealed by questionnaires and biomarker levels. Nutrition score, MEDAS score, EVOO and nuts consumption were similar between groups at baseline. At 24-28th and 36-38th gestational weeks, the intervention group had significantly higher Nutrition and MEDAS scores and nuts and EVOO intake than the standard care control group. Similarly, hydroxytyrosol and gamma-tocopherol levels were alike between groups at baseline and increased significantly in the intervention group at $24-28$ th (both $p=0.001$ ). Physical activity decreased significantly throughout pregnancy in both groups and no differences were found at any point of pregnancy between groups.

Maternal clinical, biochemical and anthropometric data are displayed in Table 3. At 24-28th gestational 
Table 1. Baseline characteristics of the clinical trial population by randomization groups

\begin{tabular}{|c|c|c|c|}
\hline & Control group $(n=337)$ & Intervention group $(n=360)$ & $p$ value \\
\hline Age, years & $32.54 \pm 5.29$ & $32.92 \pm 4.92$ & 0.331 \\
\hline \multicolumn{4}{|l|}{ Race/ethnicity } \\
\hline Caucasian & $226(67.1)$ & $244(67.8)$ & \\
\hline Hispanic & $98(29.1)$ & $109(30.3)$ & \\
\hline Others & $13(3.9)$ & $7(1.9)$ & 0.215 \\
\hline \multicolumn{4}{|l|}{ Family history of } \\
\hline Type 2 diabetes & $19(5.7)$ & $10(2.8)$ & \\
\hline MetS (>2 components) & $62(18.4)$ & $83(23.5)$ & 0.069 \\
\hline \multicolumn{4}{|l|}{ Previous history of } \\
\hline Gestational diabetes & $8(2.4)$ & $7(1.9)$ & \\
\hline Miscarriages & $108(32.0)$ & $119(33.1)$ & 0.237 \\
\hline \multicolumn{4}{|l|}{ Educational status } \\
\hline Elementary education & $31(7.6)$ & $22(6.1)$ & \\
\hline Secondary school & $132(39.2)$ & $152(42.2)$ & \\
\hline University degree & $169(50.1)$ & $185(51.4)$ & \\
\hline UNK & $5(1.5)$ & $1(0.3)$ & 0.233 \\
\hline Employment & $254(75.3)$ & $285(79.2)$ & 0.264 \\
\hline \multicolumn{4}{|l|}{ Number of pregnancies } \\
\hline Primiparous & $135(40.1)$ & $166(46.1)$ & \\
\hline Second pregnancy & $114(33.8)$ & $111(30.8)$ & \\
\hline$>2$ pregnancies & $88(26.1)$ & $83(23.1)$ & 0.119 \\
\hline \multicolumn{4}{|l|}{ Smoker } \\
\hline Never & $188(55.8)$ & $196(54.4)$ & \\
\hline Current & $25(7.4)$ & $30(8.3)$ & 0.953 \\
\hline Gestational age (weeks) at baseline & $12.1 \pm 0.5$ & $12.0 \pm 0.3$ & 0.782 \\
\hline \multicolumn{4}{|l|}{ Body weight, kg } \\
\hline Prepregnancy & $60.5 \pm 10.9$ & $59.1 \pm 9.4$ & 0.070 \\
\hline At entry & $62.5 \pm 11.4$ & $61.1+9.5$ & 0.073 \\
\hline Weight gain & $2.1 \pm 3.1$ & $1.9 \pm 2.7$ & 0.495 \\
\hline \multicolumn{4}{|l|}{ BMI, $\mathrm{kg} / \mathrm{m}^{2}$} \\
\hline Prepregnancy & $22.9 \pm 3.8$ & $22.4 \pm 3.3$ & 0.097 \\
\hline At baseline & $23.7 \pm 3.9$ & $23.2 \pm 3.4$ & 0.103 \\
\hline \multicolumn{4}{|l|}{ Blood pressure, $\mathrm{mm} \mathrm{Hg}$} \\
\hline Systolic & $105 \pm 10$ & $106 \pm 11$ & 0.116 \\
\hline Diastolic & $64 \pm 12$ & $66 \pm 9$ & 0.114 \\
\hline Fasting blood glucose, $\mathrm{mg} / \mathrm{dL}$ & $81 \pm 6$ & $80 \pm 6$ & 0.171 \\
\hline $\mathrm{HbA}_{1 \mathrm{c}}, \%, \mathrm{mmol} / \mathrm{mol}$ & $5.2 \pm 0.3(33 \pm 3)$ & $5.0 \pm 0.2(31 \pm 2)$ & 0.989 \\
\hline Cholesterol, mg/DL & $176 \pm 33$ & $172 \pm 26$ & 0.112 \\
\hline Triglycerides, mg/dL & $81 \pm 38$ & $81 \pm 43$ & 0.982 \\
\hline $\mathrm{TSH}, \mu \mathrm{UI} / \mathrm{ML}$ & $1.9 \pm 1.2$ & $2.1 \pm 1.5$ & 0.128 \\
\hline $\mathrm{T} 4 \mathrm{~L}, \mathrm{ng} / \mathrm{DL}$ & $8.6 \pm 1.5$ & $8.7 \pm 1.4$ & 0.588 \\
\hline MEDAS Score & $4.83 \pm 1.76$ & $4.97 \pm 1.71$ & 0.293 \\
\hline Nutrition Score & $0.54 \pm 3.16$ & $0.22 \pm 3.25$ & 0.193 \\
\hline Physical activity Score $>0$ & $46(14.6)$ & $35(9.7)$ & 0.142 \\
\hline
\end{tabular}

Data are mean \pm SD or number $(\%)$.

MEDAS Score, 14-point MEDAS. Physical activity score $\geq 0$, (walking daily ( $>5$ days/week) score 0: at least 30 $\mathrm{min}$. Score +1 , if $>60 \mathrm{~min}$. Score -1 , if $<30 \mathrm{~min}$. Climbing stairs (floors/day, $>5$ days a week): Score 0 , Between 4 and 16; Score $+1,>16$; Score -1 : $<4$ ).

MetS, metabolic syndrome; UNK, unknown; BMI, body mass index; MEDAS, Mediterranean diet adherence screener; $\mathrm{HbA}_{1 \mathrm{c}}$, haemoglobin. 
Table 2. Evolution of lifestyle and dietary habits throughout the pregnancy

\begin{tabular}{|c|c|c|c|c|}
\hline & At baseline & 24-28 GW & $36-38 \mathrm{GW}$ & $p^{\mathrm{a}}$ \\
\hline \multicolumn{5}{|l|}{ EVOO, mL/day } \\
\hline Control & $29 \pm 20$ & $26 \pm 22$ & $26 \pm 19$ & 0.020 \\
\hline Intervention & $28 \pm 24$ & $32 \pm 21$ & $37 \pm 25$ & 0.001 \\
\hline Mean differences (95\% CI) & $1(-2$ to 4$)$ & $-6(-8$ to -2$)$ & $-11(-16$ to -6$)$ & \\
\hline$p^{\mathrm{b}}$ & 0.534 & 0.001 & 0.0001 & \\
\hline \multicolumn{5}{|l|}{ Pistacho/Nuts, day/week } \\
\hline Control & $1.5 \pm 2.2$ & $1.4 \pm 2.2$ & $1.9 \pm 2.5$ & 0.128 \\
\hline Intervention & $1.3 \pm 2.1$ & $3.9 \pm 2.7$ & $3.1 \pm 2.8$ & 0.001 \\
\hline Mean differences (95\% CI) & $0.1(-0.2$ to 0.5$)$ & $-2.5(-2.9$ to -2.1$)$ & $-1.2(-1.8$ to -0.6$)$ & \\
\hline$p^{\mathrm{b}}$ & 0.381 & 0.0001 & 0.0001 & \\
\hline \multicolumn{5}{|l|}{ Nutrition Score } \\
\hline Control & $0.54 \pm 3.16$ & $1.09 \pm 3.29$ & $2.32 \pm 3.26$ & 0.001 \\
\hline Intervention & $0.22 \pm 3.25$ & $4.18 \pm 3.34$ & $4.65 \pm 3.44$ & 0.001 \\
\hline Mean differences (95\% CI) & $0.3(-0.2$ to 0.8$)$ & $-3.1(-3.6$ to -2.6$)$ & $-2.3(-3.1$ to -1.6$)$ & \\
\hline$p^{\mathrm{b}}$ & 0.193 & 0.0001 & 0.0001 & \\
\hline \multicolumn{5}{|l|}{ MEDAS Score } \\
\hline Control & $4.83 \pm 1.76$ & $5.83 \pm 1.63$ & $6.21 \pm 1.60$ & 0.001 \\
\hline Intervention & $4.97 \pm 1.71$ & $7.46 \pm 1.61$ & $7.52 \pm 1.77$ & 0.001 \\
\hline Mean differences (95\% CI) & $-0.1(-0.4$ to 0.1$)$ & $-1.6(-1.9$ to -1.4$)$ & $-1.3(-1.7$ to -1.0$)$ & \\
\hline$p^{\mathrm{b}}$ & 0.293 & 0.0001 & 0.0001 & \\
\hline \multicolumn{5}{|l|}{ Hydroxytyrosol, $\mu \mathrm{g} / \mathrm{L}$} \\
\hline Control & $32.6 \pm 39.8$ & $30.3 \pm 21.2$ & NA & \\
\hline Intervention & $31.0 \pm 27.2$ & $121.2 \pm 40.8$ & NA & \\
\hline Mean differences (95\% CI) & $1.6(-11.6$ to 14.8$)$ & $-91(-106$ to -76$)$ & & \\
\hline$p^{\mathrm{b}}$ & 0.809 & 0.001 & & \\
\hline \multicolumn{5}{|l|}{ Gamma-tocopherol, nmol/L } \\
\hline Control & $196.5 \pm 58.5$ & $121.3 \pm 104.1$ & NA & \\
\hline Intervention & 205.4 & $297.3 \pm 64.4$ & NA & \\
\hline Mean differences (95\% CI) & $-8.9(-50.7$ to 33.0$)$ & $-176(-235$ to -117$)$ & & \\
\hline$p^{\mathrm{b}}$ & 0.699 & 0.001 & & \\
\hline \multicolumn{5}{|l|}{ Physical Activity Score $>0$} \\
\hline Control & $46(12.4)$ & $24(7.1)$ & $7(2.0)$ & 0.001 \\
\hline Intervention & $34(9.4)$ & $25(6.9)$ & $29(8.1)$ & 0.001 \\
\hline$p^{\mathrm{b}}$ & 0.142 & 0.568 & 0.189 & \\
\hline
\end{tabular}

Data are mean \pm SD or number $(\%)$.

$p^{\text {a }}$ denote differences within each group compared to baseline (ANOVA).

$p^{\mathrm{b}}$ denote differences between groups at different stages of pregnancy $(t$ test).

Changes, differences at 24-28 GW and 36-38 GW in relation to baseline.

MEDAS Score, 14-point MEDAS. Physical Activity. Score $\geq 0$, walking daily ( $>5$ days week); score 0 , at least $30 \mathrm{~min}$; score +1 , if $>60 \mathrm{~min}$; score -1 , if $>30 \mathrm{~min}$. Climbing stairs (floors/day, $>5$ days a week); score 0 , between 4 and 16 ; and score $+1,>16$; score $-1:<4$.

GW, gestational weeks; EVOO, extra virgin olive oil; MEDAS, Mediterranean diet adherence screener; NA, no applicable.

weeks, the intervention group had lower mean fasting glucose and $\mathrm{HbA}_{1 \mathrm{c}}$ levels as compared to the standard care control group. At 36-38th gestational weeks, lower mean fasting glucose and $\mathrm{HbA}_{1 \mathrm{c}}$ levels remained significantly lower in the intervention group. Body weight was significantly lower in the intervention group at 24-28th gestational weeks. However, at 36-38th gestational weeks it was similar between groups. Gestational weight gain was also similar between groups. No differences were observed between groups regarding rates of adequate, insufficient or excessive weight gain.

The results of the crude RR analysis of maternal and neonatal outcomes are shown in Table 4. Crude RR showed that the intervention was associated with a significant re- 
Table 3. Maternal pregnancy clinical and laboratory data groups

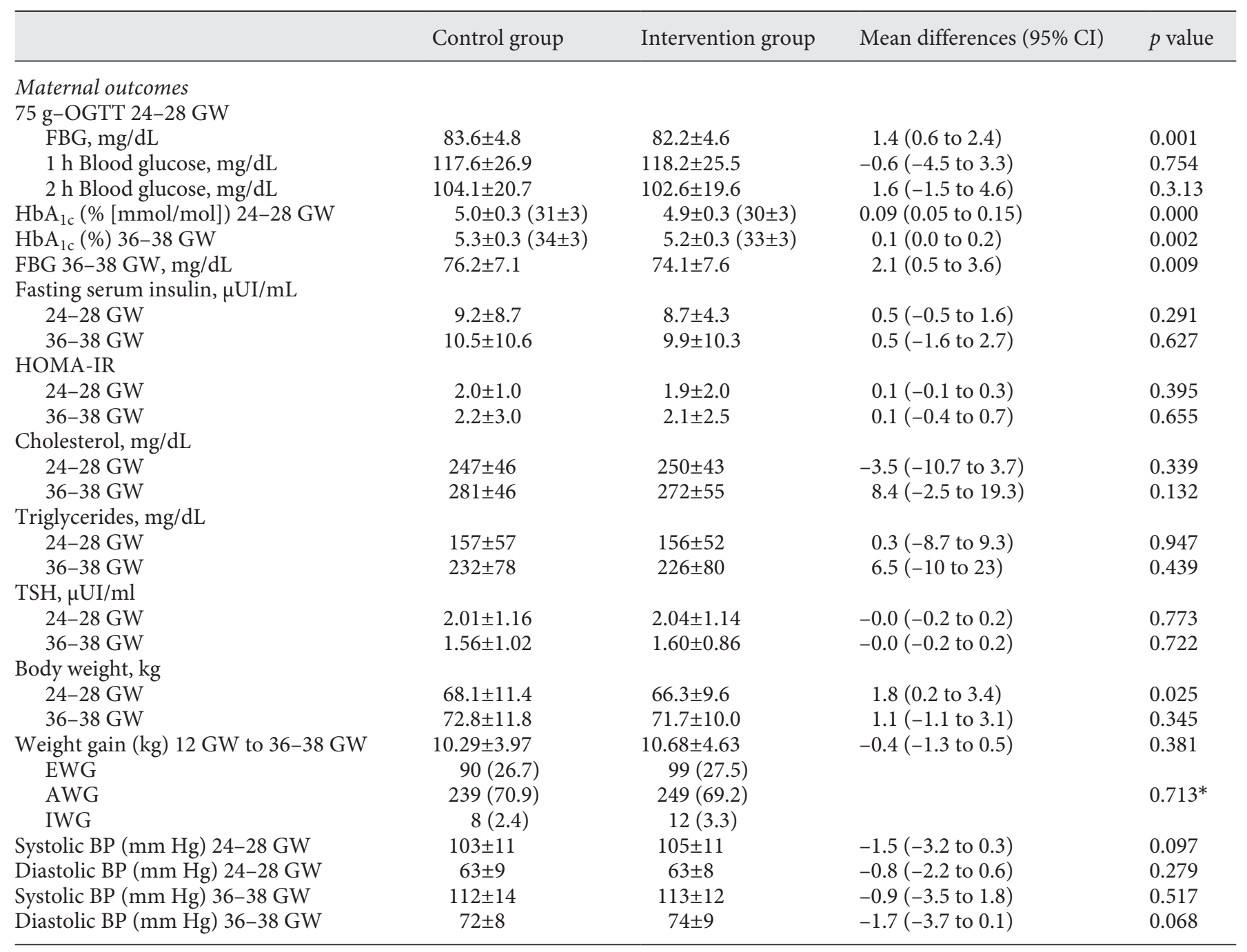

* $\chi^{2}$ test performed for analysis of categorical variables.

OGTT, oral glucose tolerance test; FBG, fasting blood glucose; GW, gestational weeks; BP, blood pressure; EWG, excessive weight gain; AWG, adequate weight gain; IWG, insufficient weight gain; $\mathrm{HbA}_{1 \mathrm{c}}$, glycated haemoglobin.

duction of the risk of having at least one event of the CMFOs (0.48 [0.37-0.63]; $p=0.0001)$. Five women need to be treated/intervened to prevent one event of the CMFOs $(\mathrm{NNT}=5)$. It was also associated with a significantly lower risk of having urinary tract infections $0.37([0.20-0.66], p=$ $0.001 ; \mathrm{NNT}=14)$, emergency C-sections $0.28([0.13-0.64]$, $p=0.002 ; \mathrm{NNT}=20)$, perineal trauma $0.22([0.12-0.41]$, $p=0.001 ; \mathrm{NNT}=10)$, large-for-gestational-age $0.25([0.07$ $0.90], p=0.034$; NNT $=40)$ and small-for-gestational-age new-borns $0.26([0.08-0.80], p=0.018$; NNT = 33). Smallfor-gestational-age new-borns were associated with insufficient weight gain $0.25([0.08-0.77], p=0.016)$.

MedDiet and Pregnancy Outcomes

\section{Discussion}

This was a sub-analysis of the St. Carlos GDM Prevention Study evaluating the effect of a MedDiet, supplemented with EVOO and pistachios, on maternal and foetal outcomes of women without GDM.

Results indicate that a MedDiet, with a promotion of EVOO and nuts consumption, as opposed to restricting fats, reduces in more than $50 \%$ the risk of having at least 1 event of composite maternofoetal outcomes. This dietary pattern was also associated with a significant reduction in the risk of small-for-gestational-age, large-for- 
Table 4. Maternal pregnancy and neonatal outcomes by groups

Control group $(n=337) \quad$ Intervention group $(n=360) \quad p$ value $\quad \mathrm{RR}(95 \% \mathrm{CI})$

\begin{tabular}{|c|c|c|c|c|c|}
\hline \multicolumn{6}{|l|}{ Maternal outcomes } \\
\hline Pregnancy-induced hypertension & $11(3.3)$ & $13(3.6)$ & 0.484 & & \\
\hline Preeclampsia & $4(1.2)$ & $7(1.9)$ & 0.311 & & \\
\hline Albuminuria & $4(1.2)$ & $2(0.6)$ & 0.313 & & \\
\hline Urinary tract infection & $40(11.9)$ & $17(4.7)$ & 0.001 & $0.37(0.20-0.66)$ & 14 \\
\hline \multicolumn{6}{|l|}{ Delivery } \\
\hline Vaginal eutocic & $240(71.2)$ & $256(71.1)$ & & & \\
\hline Instrumental & $48(14.2)$ & $52(14.4)$ & & & \\
\hline Cesarean section & $49(14.5)$ & $52(14.4)$ & 0.997 & & \\
\hline Emergency-CS & $25(7.4)$ & $8(2.2)$ & 0.002 & $0.28(0.13-0.64)$ & 20 \\
\hline Perineal trauma & $49(14.5)$ & $13(3.6)$ & 0.001 & $0.22(0.12-0.41)$ & 10 \\
\hline \multicolumn{6}{|l|}{ Neonatal Outcomes } \\
\hline Gestational age at birth, weeks & $39.6 \pm 1.3$ & $39.7 \pm 1.3$ & 0.716 & & \\
\hline$<37 \mathrm{GW}$ & $11(3.6)$ & $4(1.1)$ & 0.067 & $0.33(0.11-1.06)$ & 40 \\
\hline Birthweight, $g$ & $3,219 \pm 465$ & $3,269 \pm 396$ & 0.275 & & \\
\hline Percentile & $46.1 \pm 27.1$ & $50.3 \pm 27.5$ & 0.076 & & \\
\hline Length, cm & $49.2 \pm 2.0$ & $49.3 \pm 2.1$ & 0.575 & & \\
\hline Percentile & $38.8 \pm 27.7$ & $40.7 \pm 28.9$ & 0.440 & & \\
\hline LGA >90 percentile & $11(3.3)$ & $3(0.8)$ & 0.034 & $0.25(0.07-0.90)$ & 40 \\
\hline$>4,500, \mathrm{~g}$ & 0 & 0 & NA & & \\
\hline SGA $<10$ percentile & $14(4.2)$ & $4(1.1)$ & 0.018 & $0.26(0.08-0.80)$ & 33 \\
\hline pH cord blood & $7.28 \pm 0.18$ & $7.27 \pm 0.08$ & 0.524 & & \\
\hline Apgar score at $1 \mathrm{~min}$ & $8.8 \pm 0.7$ & $8.9 \pm 0.7$ & 0.699 & & \\
\hline Apgar score at $5 \mathrm{~min}$ & $10 \pm 3.7$ & $10 \pm 3.8$ & 0.883 & & \\
\hline \multicolumn{6}{|l|}{ Neonatal } \\
\hline Hypoglycemia & $4(1.2)$ & $3(0.8)$ & 0.464 & & \\
\hline Respiratory distress & $3(1.8)$ & $3(0.8)$ & 0.625 & & \\
\hline Hyperbilurrubinemia & $22(6.5)$ & $17(4.7)$ & 0.192 & & \\
\hline NICU/observation & $6(1.8)$ & $6(1.7)$ & 0.908 & & \\
\hline Composite maternofetal outcomes & $87(25.8)$ & $32(8.8)$ & 0.0001 & $0.47(0.35-0.64)$ & 5 \\
\hline
\end{tabular}

Composite of maternofoetal outcomes at least one of: emergency C-section, perineal trauma, pregnancy-induced hypertension and preeclampsia, prematurity, large-for-gestational-age and small-for gestational age.

$\mathrm{RR}$, relative risk; NNT, number-needed-to-treat; LGA, large for gestational age; SGA, small for gestational age; NICU, neonatal intensive care unit; NA, not applicable.

gestational-age new-borns, urinary tract infections and emergency C-sections and had favourable effects on $\mathrm{HbA}_{1 \mathrm{c}}$ levels and gestational weight gain in women without GDM.

As reflected by the Nutrition and MEDAS scores, as well as by the intake of EVOO and nuts and biomarker levels, women in the intervention group improved their nutritional habits as compared with the control group. However, the mean daily intake of EVOO in the intervention group showed that women did not reach the optimal recommended amount. This shows that despite being encouraged to liberalize the consumption of this fat, women did not consume it in excess. In contrast, the mean intake of nuts indicated that women did comply with the minimum amount recommended. In relation to physical ac- tivity, unfortunately both groups of women reduced the frequency throughout the pregnancy.

Considering that women from both groups were normoglycemic, the intervention group had significantly lower fasting glucose and $\mathrm{HbA}_{1 \mathrm{c}}$ levels at 24-28 and 3638 th gestational weeks than the control group. This could explain why the rate and risk of large-for-gestational-age was significantly lower in the intervention group as compared with the control group. Birth weight $>90$ th percentile has been shown to have a linear relation with fasting glucose levels. Women with fasting glucose levels between 75 and $79 \mathrm{mg} / \mathrm{dL}$ have a 1.37 increased risk of having large-for-gestational-age new-borns than those with $<75 \mathrm{mg} / \mathrm{dL}$ [24]. Moreover, this lower rate of large-forgestational-age could in turn account for the lower rates 
of emergency $\mathrm{C}$-sections and perineal trauma found in the intervention group $[25,26]$.

Most studies evaluating the effect of maternal nutrition focus on its relationship with foetal growth $[5,7,27$, 28]. Following a dietary pattern rich with a higher intake of fruits, vegetables, fish and poultry and lower intake of meat and fat of animal origin has been associated with lower small-for-gestational-age risk [5]. In contrast, a western diet has been associated with a higher risk of small-for-gestational-age and large-for-gestational-age [3]. Similarly, women with a high-quality diet have shown to have a reduced risk of delivering new-borns with foetal growth restriction [29].

Small-for-gestational-age new-borns rates were also significantly lower in the intervention group. There were no differences between groups in the rates of hypertensive disorders and smoking habits. However, these lower rates of small-for-gestational-age new-borns found could be related to the lower rates of urinary tract infections, which have been associated with higher risk of small-for-gestational-age new-borns [30, 31] and prematurity [32]. The MedDiet enhanced with EVOO and nuts could have had a direct influence on the lower incidence of urinary tract infections. The richness of phenolic compounds found in this type of diet could have potentially positively affected immunomodulation and urinary microbiota [33-35], and thus, the lower events of urinary tract infections.

The MedDiet has been associated with lower rates and risk of prematurity $[3,6,36]$. Our results revealed that the rates of prematurity in the intervention group did not differ from the standard-care control group, consistent with results from the MoBa study [37]. Nevertheless, our results did indicate a non-significant tendency of lower rates of prematurity in the intervention group, perhaps representing a type 2 statistical error where no significant differences were found due to the sample size.

The maternal diet seems to have a potential impact in modulating gut and placental microbiome [38]. We might hypothesize that the reduction in the risk of developing pregnancy complications could be due to the effect of the MedDiet on modulating the placental microbiome and its beneficial impact on pregnancy outcomes [39].

The MedDiet has been attributed a number of health benefits, mainly due to the presence of components such as monounsaturated and polyunsaturated fatty acids and phytochemicals [40]. These are abundantly present in both EVOO (a rich source of phenolic acids, phenolic alcohols, secoiridoids, and flavonoids) and nuts (a rich source of phenols, carotenoids, flavonoids, stilbenes, proanthocyanidins and phytosterols). As compared to other olive oils,
EVOO has the highest content of phytochemicals. The production of EVOO only involves mechanical processing, minimally altering olives nutritional properties. On the other hand, pistachios have higher levels of unsaturated fatty acids, fibre, magnesium, lutein, phytosterols, xanthophyll, carotenoids and $\gamma$-tocopherol than other nuts. Pistachio consumption has also been associated with lowering postprandial glycaemia, improving oxidative stress and endothelial function [40]. Moreover, roasted versus raw pistachios seem to contain higher amounts of flavonoids and have better organoleptic properties [41].

This sub analysis shows that encouraging the consumption of EVOO and nuts in pregnant women does not translate in an excessive intake. Current guidelines for pregnancy highlight the importance of reducing total fat intake, with the concern that the opposite will lead to an excessive weight gain. Results from this study do not support this recommendation.

\section{Limitations}

This study has certain limitations. First, the original study was designed to answer a different question to the one presented in this manuscript [15]. Regardless, this secondary analysis yielded interesting results. Moreover, women in the intervention group did not comply with the minimum daily intake EVOO, $>40 \mathrm{~mL} /$ day. If these women had consumed at least $40 \mathrm{~mL} /$ day, maybe other complications that were not significantly different would have been. Notwithstanding, the intervention group compared to the standard care control group maintained a significantly higher consumption of EVOO throughout the pregnancy.

\section{Conclusions}

Adhering to nutritional recommendations based on a MedDiet enhanced with EVOO and nuts during pregnancy was associated with a reduction in over $50 \%$ the risk of developing at least one event of a CMFOs in normoglycemic women. Current recommendations to limit fat consumption during pregnancy need to be revised. Recommendations based on a MedDiet that liberalizes EVOO and nuts consumption should be considered an adequate dietary pattern to follow during pregnancy. The potential effect of following this dietary pattern during pregnancy on postpartum maternal and infant health is being currently evaluated. 


\section{Acknowledgements}

We wish to acknowledge the kind collaboration of: IRIAF - Instituto Regional de Investigación Agroalimentaria y Forestal de Castilla La Mancha (C.I.A. El Chaparrillo, Ciudad Real), Olive Oils from Spain (www.oliveoilsfromspain.org - Organización Interprofesional del Aceite de Oliva Español). Our deep appreciation goes to the administrative staff, nurses and dieticians from the Laboratory Department (Marisol Sanchez Orta, Maria Victoria Saez de Parayuelo, Luzdivina Fernandez Muñoz, Ana Rosa Bedia and Felix Calzada) and the Pregnancy and Diabetes Unit (Miriam Lara, Amparo Sabaté Garcia, Rosa M Mendez Gomez and Consuelo Auñón Pereda).

\section{Ethics Approval and Consent to Participate}

The study was approved by the Ethics Committee of Hospital Clínico San Carlos and conducted according to the Helsinki Declaration. All women signed a letter of informed consent.

\section{Disclosure Statement}

The authors declare that they have no competing interests to disclose.

\section{Funding Source}

This study was supported by the Fundación para Estudios Endocrinometabolicos, IdISSC Hospital Clínico San Carlos (Madrid), Universidad Complutense of Madrid, Medicine Department, the Instituto de Salud Carlos III (ISCIII) of Spain (PI14/01563), integrated in the Plan National I+D+I AES 2013-2016, Fondo Europeo de Desarrollo Regional (FEDER) and the Sociedad de Endocrinología Nutrición y Diabetes dela Comunidad de Madrid (IPI/2017/ NR2) available at http://www.sendimad.org/nuevasendimad/ayuda-a-la-investigacion-historico-premiados. The role of the funding source: The funders had no role in the design and conduct of the study; collection, management, analysis, and interpretation of the data; preparation, review, and approval of the manuscript; and decision to submit the manuscript for publication. These were responsibilities of the authors alone and independent of the funders.

\section{Authors Contribution}

Conceptualization: A.L.C.-P., C.A.-B., N.G.T., A.D., E.B., M.A.H., M.J.T., I.R., M.C., and M.A.R. Data curation: A.L.C.-P., C.A.-B., N.G.T., A.D., M.F., L.V., C.F., J.V., I.J., N.I., M.J.T., I.O., F.J.I., I.R., I.M., C.M., A.B. and M.A.R. Formal analysis: A.L.C.-P., C.A.-B., N.G.T., A.D., M.F., E.B., I.J., P.M., A.B. and M.A.R. Funding acquisition: A.L.C.-P., C.A.-B., and N.G.T. Investigation: A.L.C.-P., C.A.B., N.G.T., A.D., M.F., E.B., L.V., C.F., J.V., I.J., M.A.H., N.I., M.J.T., A.C., F.J.I., I.R., P.M., C.M., A.B., M.C., and M.A.R. Methodology: A.L.C.-P., C.A.-B., N.G.T., A.D., M.F., E.B., L.V., C.F., J.V., I.J., M.A.H., N.I., M.J.T., A.C., I.O., F.J.I., I.R., P.M., C.M., A.B., M.C., and M.A.R. Supervision: A.L.C.-P., M.F., M.C. and M.A.R. Validation and visualization: A.L.C.-P. and M.F. Drafting and writing of the original article: A.L.C.-P., C.A.B., N.G.T., A.D., and I.R. Writing - review and editing: A.L.C.-P., C.A.-B., N.G.T., A.D., I.R., and M.A.R.

\section{Availability of Data and Material}

The datasets generated during and/or analysed during the current study are available from the corresponding author on reasonable request. All data generated or analysed during this study are included in this published article.

\section{References}

1 Markovic TP, Muirhead R, Overs S, Ross GP, Louie JC, Kizirian N, et al: Randomized controlled trial investigating the effects of a lowglycemic index diet on pregnancy outcomes in women at high risk of gestational diabetes mellitus: the GI baby 3 study. Diabetes Care 2016;39:31-38.

2 Brantsæter AL, Haugen M, Myhre R, Sengpiel V, Englund-Ögge L, Nilsen RM, et al: Diet matters, particularly in pregnancy - results from MoBa studies of maternal diet and pregnancy outcomes. Norsk Epidemiol. 2014;24: 63-77.

3 Chen X, Zhao D, Mao X, Xia Y, Baker PN, Zhang $\mathrm{H}$ : Maternal dietary patterns and pregnancy outcome. Nutrients 2016;8:351.

4 Freitas-Vilela AA, Pearson RM, Emmett P, Heron J, Smith ADAC, Emond A, et al: Maternal dietary patterns during pregnancy and intelligence quotients in the offspring at 8 years of age: findings from the ALSPAC cohort. Matern Child Nutr 2018;14:e12431.

5 Knudsen VK, Orozova-Bekkevold IM, Mikkelsen TB, Wolff S, Olsen SF: Major dietary patterns in pregnancy and fetal growth. Eur J Clin Nutr 2008;62:463-470.

6 Gresham E, Bisquera A, Byles JE, Hure AJ: Effects of dietary interventions on pregnancy outcomes: a systematic review and meta-analysis. Matern Child Nutr 2016;12:5-23.

7 da Silva Lopes K, Ota E, Shakya P, Dagvadorj A, Balogun OO, Peña-Rosas JP, et al: Effects of nutrition interventions during pregnancy on low birth weight: an overview of systematic reviews. BMJ Glob Health 2017;2:e000389.

8 Borge TC, Aase H, Brantsæter AL, Biele G: The importance of maternal diet quality during pregnancy on cognitive and behavioural outcomes in children: a systematic review and meta-analysis. BMJ Open 2017;7:e016777.
9 Calkins K, Devaskar SU: Fetal origins of adult disease. Curr Probl Pediatr Adolesc Health Care 2011;41:158-176.

10 Lee HS: Impact of maternal diet on the epigenome during In utero life and the developmental programming of diseases in childhood and adulthood. Nutrients 2015;7:94929507.

11 Geraghty AA, Lindsay KL, Alberdi G, McAuliffe FM, Gibney ER: Nutrition during pregnancy impacts offspring's epigenetic status-evidence from human and animal studies. Nutr Metab Insights 2016;8(suppl 1):41-47

12 Lamminpää $R$, Vehviläinen-Julkunen $K$, Schwab U: A systematic review of dietary interventions for gestational weight gain and gestational diabetes in overweight and obese pregnant women. Eur J Nutr 2017;57:17211736. 
13 Martínez-González M, Hershey M, Zazpe I, Trichopoulou A: Transferability of the mediterranean diet to non-mediterranean countries. What is and what is not the mediterranean diet. Nutrients 2017;9:pii:E1226.

14 Estruch R, Martínez-González MA, Corella D, Salas-Salvadó J, Fitó M, Chiva-Blanch G, et al: Effect of a high-fat mediterranean diet on bodyweight and waist circumference: a prespecified secondary outcomes analysis of the PREDIMED randomised controlled trial. Lancet Diabetes Endocrinol 2016;4:666-676.

15 Assaf-Balut C, García de la Torre N, Durán A, Fuentes M, Bordiú E, del Valle L, et al: A mediterranean diet with additional extra virgin olive oil and pistachios reduces the incidence of gestational diabetes mellitus (GDM): a randomized controlled trial: the St. Carlos GDM prevention study. PLoS One 2017;12: e0185873.

16 SEGO. Protocolo SEGO: Control prenatal del embarazo normal. Prog Obstet Ginecol 2011; 54:330-349.

17 The Diabetes and Nutrition Study Group of the Spanish Diabetes Association: Diabetes Nutrition and Complications Trial: Trends in nutritional pattern between 1993 and 2000 and targets of diabetes treatment in a sample of Spanish people with diabetes. Diabetes Care 2004;27:984-987.

18 Schroder H, Fito M, Estruch R, MartinezGonzález MA, Corella D, Salas-Salvadó J, et al: A short screener is valid for assessing mediterranean diet adherence among older Spanish men and women. J Nutr 2011;141:11401145.

19 Cicerale S, Lucas L, Keast R: Biological activities of phenolic compounds present in virgin olive oil. Int J Mol Sci 2010;11:458-479.

20 Hernández-Alonso P, Salas-Salvadó J, Baldrich-Mora M, Juanola-Falgarona M, Bulló M: Beneficial effect of pistachio consumption on glucose metabolism, insulin resistance, inflammation, and related metabolic risk markers: a randomized clinical trial. Diabetes Care 2014;37:3098-3105.

21 Hutcheon JA, Platt RW, Abrams B, Himes KP, Simhan HN, Bodnar LM: Pregnancy weight gain charts for obese and overweight women. Obesity (Silver Spring) 2015;23:532535.
22 Kapadia MZ, Park CK, Beyene J, Giglia L, Maxwell C, McDonald SD: Weight loss instead of weight gain within the guidelines in obese women during pregnancy: a systematic review and meta-analyses of maternal and infant outcomes. PLoS One 2015;10: e0132650.

23 Wong T, Barnes RA, Ross GP, Cheung NW, Flack JR: Are the institute of medicine weight gain targets applicable in women with gestational diabetes mellitus? Diabetologia 2017; 60:416-423.

24 Metzger BE, Lowe LP, Dyer AR, Trimble ER, Chaovarindr U, Coustan DR, et al: Hyperglycemia and adverse pregnancy outcomes. N Engl J Med 2008;358:1991-2002.

25 Turkmen S, Johansson S, Dahmoun M: Foetal macrosomia and foetal-maternal outcomes at birth. J Pregnancy 2018;2018:4790136.

26 Froehlich RJ, Sandoval G, Bailit JL, Grobman WA, Reddy UM, Wapner RJ, et al: Association of recorded estimated fetal weight and cesarean delivery in attempted vaginal delivery at term. Obstet Gynecol 2016;128:487494.

27 Thompson JM, Wall C, Becroft DM, Robinson E, Wild CJ, Mitchell EA: Maternal dietary patterns in pregnancy and the association with small-for-gestational-age infants. $\mathrm{Br} \mathrm{J}$ Nutr 2010;103:1665-1673.

28 Coelho Nde L, Cunha DB, Esteves AP, Lacerda EM, Theme Filha MM: Dietary patterns in pregnancy and birth weight. Rev Saude $\mathrm{Pu}-$ blica 2015;49:62.

29 Rodríguez-Bernal CL, Rebagliato M, Iñiguez C, Vioque J, Navarrete-Muñoz EM, Murcia $M$, et al: Diet quality in early pregnancy and its effects on fetal growth outcomes: the Infancia y medio ambiente (childhood and environment) mother and child cohort study in Spain. Am J Clin Nutr 2010;91:1659-1666.

30 Mazor-Dray E, Levy A, Schlaeffer F, Sheiner E: Maternal urinary tract infection: is it independently associated with adverse pregnancy outcome? J Matern Fetal Neonatal Med 2009; 22:124-128.

31 Bolton M, Horvath DJ Jr, Li B, Cortado H, Newsom D, White $\mathrm{P}$, et al: Intrauterine growth restriction is a direct consequence of localized maternal uropathogenic Escherichia coli cystitis. PLoS One 2012;7:e33897.
32 Brown RG, Marchesi JR, Lee YS, Smith A, Lehne B, Kindinger LM, et al: Vaginal dysbiosis increases risk of preterm fetal membrane rupture, neonatal sepsis and is exacerbated by erythromycin. BMC Med 2018;16:9.

33 Puertollano MA, Puertollano E, Álvarez de Cienfuegos G, de Pablo MA: Significance of olive oil in the host immune resistance to infection. Br J Nutr 2007;98(suppl 1):S54-S58.

34 Martín-Peláez S, Mosele JI, Pizarro N, Farràs M, de la Torre R, Subirana I, et al: Effect of virgin olive oil and thyme phenolic compounds on blood lipid profile: implications of human gut microbiota. Eur J Nutr 2017;56: 119-131.

35 Hernández-Alonso P, Cañueto D, Giardina S, Salas-Salvadó J, Cañellas N, Correig X, et al: Effect of pistachio consumption on the modulation of urinary gut microbiota-related metabolites in prediabetic subjects. J Nutr Biochem 2017;45:48-53.

36 Khoury J, Henriksen T, Christophersen B, Tonstad S: Effect of a cholesterol-lowering diet on maternal, cord, and neonatal lipids, and pregnancy outcome: a randomized clinical trial. Am J Obstet Gynecol 2005; 193:12921301.

37 Meltzer HM, Brantsæter AL, Nilsen RM, Magnus P, Alexander J, Haugen M: Effect of dietary factors in pregnancy on risk of pregnancy complications: results from the Norwegian mother and child cohort study. Am J Clin Nutr 2011;94(6 suppl):1970S-1974S.

38 Edwards SM, Cunningham SA, Dunlop AL, Corwin EJ: The maternal gut microbiome during pregnancy. MCN Am J Matern Child Nurs 2017;42:310-317

39 Zheng J, Xiao X, Zhang Q, Mao L, Yu M, Xu $\mathrm{J}$ : The placental microbiome varies in association with low birth weight in full-term neonates. Nutrients 2015;7:6924-6937.

40 Billingsley HE, Carbone S: The antioxidant potential of the mediterranean diet in patients at high cardiovascular risk: an in-depth review of the PREDIMED. Nutr Diabetes 2018 ; $8: 13$.

41 Ghazzawi HA, Al-Ismail K: A comprehensive study on the effect of roasting and frying on fatty acids profiles and antioxidant capacity of almonds, pine, cashew, and pistachio. J Food Qual 2017;2017:1-8. 